\title{
Functioning of the Primary Aquifer Relating to the Maider Basin, Morocco: Case of the Ordovician aquifer.
}

\author{
E. Ben-said ${ }^{* 1}, A$. Boukdir $^{1}, A$. Mahboub $^{2}, A$. Younsi $^{3} A$. Zitouni $^{1}, L \cdot$ Alili $^{1}, H \cdot$ Ikhmerdi $^{1}$. \\ ${ }^{1}$ Faculty of Sciences and Techniques, University Sultan Moulay Slimane, Béni Mellal, Morocco. \\ ${ }^{2}$ Guir-ziz-rheris Hydraulic Basin Agency, Errachidia, Morocco. \\ ${ }^{3}$ Faculty of Sciences /University Choaib Doukali, Eljadida, Morocco.
}

\begin{abstract}
The basin of Maider is limited northly by the vast ensemble Oriental Saghro-Ougnate, from the east by the Tafilalet plain, from the west by the oriental Jbel Bani, finally from the south and south-east by the Cretaceous Hamada of Kern-Kem. During last decades, groundwater in the basin of Maider, is confronting degradation in both cases: Quantitative and qualitative, as a result of the drought, the overexploitation and the salinization. The aim of this action research is to understand the current state of water resources in the area of stady. At the end of this work, we can get the following conclusions: the general flow of the ordovician aquifer is always directed from the north to the south-east of the basin by following the principal axes of the wadis:Taghbalt ,Hssiya and Fezzou. The recharge of the aquifer is primarily done, either by the underground flow, or by the surface runoff of torrential waters from the upstream of Jbel Saghro. The piezometric anomaly noticed at the level of Ait Saàdane, explained by overexploitation linked to the needs of irrigation water. The physicochemical approach for the Maider basin identifies two essential factors of the salinisation of groundwater: the dissolution of the aquifer which is rich in minerals with high temperature on the one hand, and the decrease of the piezometric surface due to the overexploitation and drought on the other hand.
\end{abstract}

Key words: Maider, groundwater, drought, overexploitation, salinization, flux, physicochemical.

\footnotetext{
${ }^{*}$ Email of corresponding : hbensaid40@,gmail.com
} 


\section{Introduction:}

In Morocco, particularly in the anti-atlas domain, water is one of the major problems because it represents a limiting factor key to sustainable development, as it improves the quality of life and peace, bearing hard circumstances as arid climate and lack of groundwater reserves.

During last decades, the groundwater in the Maider basin object of this study is increasingly exploited as a result of sharp increase of water needs, (traditional irrigation), of drought and of the climate semi-desert characterizing this region. within this framework, a good understanding of the functioning of the aquifers of the study area and the use of an appropriate management of water resources, are needed.

The quality of groundwater in the basin, which is moreover degraded, is a true challenge not less important than the scarcity of this vital resource.

This action research, is to apprehend the hydrogeological operation of the Paleozoic aquifer relating the basin Maider in function of the piezometric characteristics, hydrodynamic and hydrochemical of environment; special attention to the knowledge of the water of the Ordovician sandstone which can be a perennial resource of water in the basin.

This approach is carried out thanks to an inventory of water points comprising a hundred of boreholes and wells located in the basin, through measurement of the piézométrie, physico-chemical parameters and the call to the hydrodynamic data points of water during the pumping test.

\section{Description of the area of study:}

The area of study as a whole located in the Anti-Atlas, constitutes at the same time southern part and eastern part of this area; it is limited northly by the broad set Saghro orientalOugnate, from east by the plain of the Tafilalt, and from the west by the Jbel Bani oriental, finally from the south and south-east by the Cretaceous Hamada of Kern-Kem [1].

On this watershed, precipitations are very low, the average annual rainfall observed at the meteorological stations of Tazarine and Alnif, on the period 1982-2007, is respectively of $93 \mathrm{~mm}$ and $86 \mathrm{~mm}$; most of the rain $(>50 \%)$ is concentrated between October and February, these precipitations vary from $200 \mathrm{~mm}$ on Jbel Saghro to $87,5 \mathrm{~mm}$ on the plains of Nkoub and Alnif, and achieved less than $50 \mathrm{~mm}$ on the plain of the Maider basin. The topography of the basin is varied, with altitudes between $2692 \mathrm{~m}$ to the upstream (NNW) and $613 \mathrm{~m}$ in the outlet (Daya-el- Maïder SE). The socio-economic activity, in the basin of Maider where the inhabitants number is 418450 (according to the 
general census of Morocco in 2014) is essentially agricultural and pastoral [1] nevertheless the mining activity occupies economic importance in the region [2]. The density of the population close to $34 \mathrm{hab} / \mathrm{km} 2$, knows an annual growth of $0.58 \%$ for the period (2004-2014).

The rocks are essentially sedimentary and metamorphic formations of the anti- atlas domain, dated Paleozoic whose lithologically can be presented as of the shale, sandstone and limestone [3]. Concerning water resources, the potential aquifers, although the reserves are of little important, are Ordovician age essentially sandstone and in Devonian limestone [4].

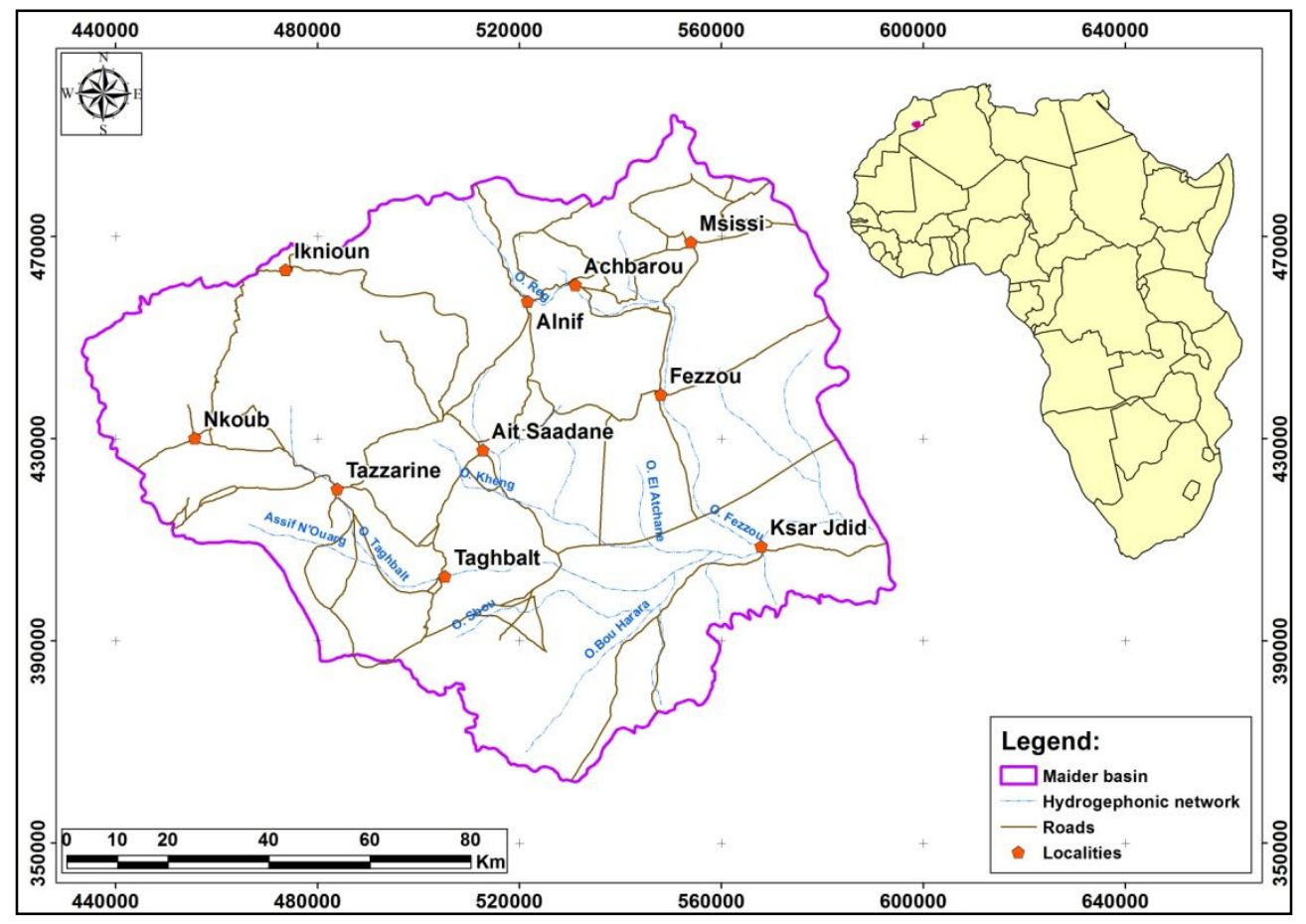

Fig. 1: Geographical situation of the Maider basin 


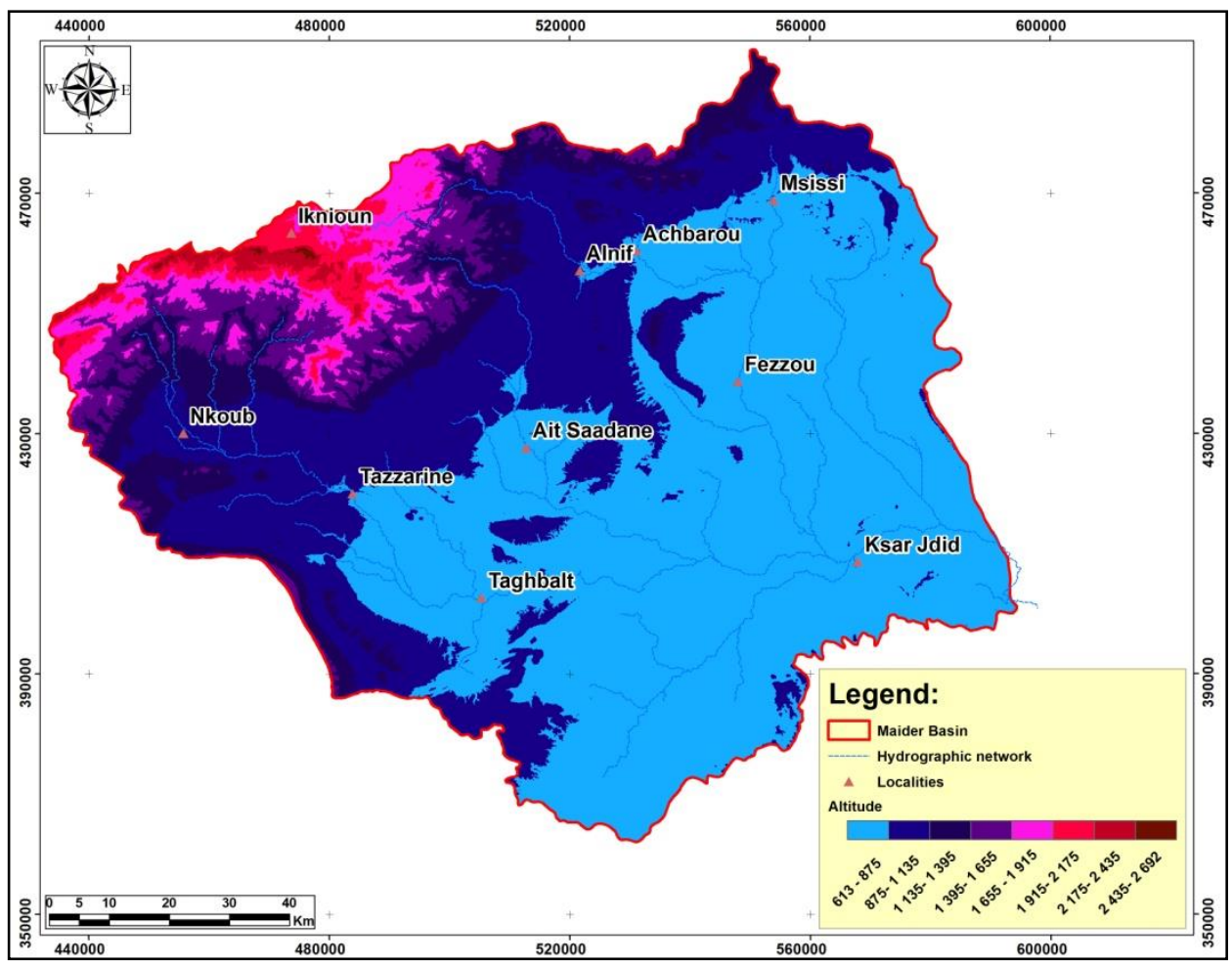

Fig. 2: Digital Terrain Model of Maider basin.

\section{Data and Methods:}

The methodological approach proposed in this study is based on the collection, treatment and the analysis of the entire piezometric and hydrodynamic data relative to the basin studied. The acquisition of data constitutes the main step in the realization and the functioning of this study. A part of the data used have been acquired from the campaigns of the measures and the technical data sheets of many wells drilled in the basin, in the framework of the partnership with the Guir-Ziz-Rheris Hydraulic Basin Agency.

The hydrochemical data are incorporated the physicochemical parameters: temperature, $\mathrm{pH}$, electrical conductivity (EC, $\mathrm{A}^{\prime} 258 \mathrm{C}$ ) on a hundred wells. The follow-up of the piézometry is also been carried out on the same network of water points for the three drowned levels that the basin contains: Ordovician, Devonian and Cambrian.

The Hydrodynamic data are got from 117 water points distributed between the borehole and the wells; it is in particular parameter of debit and transmissivity. After treatment of the serie of gotten data, this undergoes a representation of Krigeage method on the whole basin.

Furthermore, the use of a platform of Geographic Information System (GIS tools), occupies a great importance in the achievement of this work. Indeed the elaboration of 
piezometric maps and other cartographic documents, which will be shown below, are useful for the confection of the study.

\section{Results and Discussion: \\ 4.1 Piézometry and structure of flow:}

In order to highlight the current state of water resources in the Maider basin, we have established the piezometric map for the Ordovician aquifer on the basis of the statements of the year 2017.

The analysis of this piezometric map (Fig 3) shows that the general flow of the ordovician aquifer is always directed from the north to the south-east of the basin by following the principal axes of the wadis: Taghbalt, Hssiya and Fezzou. Considering that the area of study do annually receives more than $90 \mathrm{~m}$ of precipitations, it is clearly shown that the recharge of the aquifer is primarily done, either by the underground flow, or by the Surface runoff of torrential waters through Jbel Saghro. According to this map we can differentiate several zones by their hydraulic gradient:

- The zone center and southeast of the basin are characterized by a very low hydraulic gradient which varies between 0.7 to $0.3 \%$. These variations of the Gradient reflect an easy flow linked to topography plain of the area;

- The Northwest Zone of the basin is characterized by a low hydraulic gradient of the order of 1 per cent. In this area, the tightening of the isopiestic lines is linked to poor hydrodynamic characteristics of the aquifer;

The North-East area (north of the axis Alnif-Mssici) of the basin where the hydraulic gradient is important to the order of $4 \%$ for the current state (2017), is distinguished by high values that can be attributed to poor permeabilities and the tilt of the substratum at this level.

Noting the existence of an anomaly in piezometric level of Ait Saadane in the center of the basin, materialized by the curve $750 \mathrm{~m}$, that can be explained by the overexploitation of the aquifer because this area has experienced in recent years a pronounced extension of irrigated areas. 


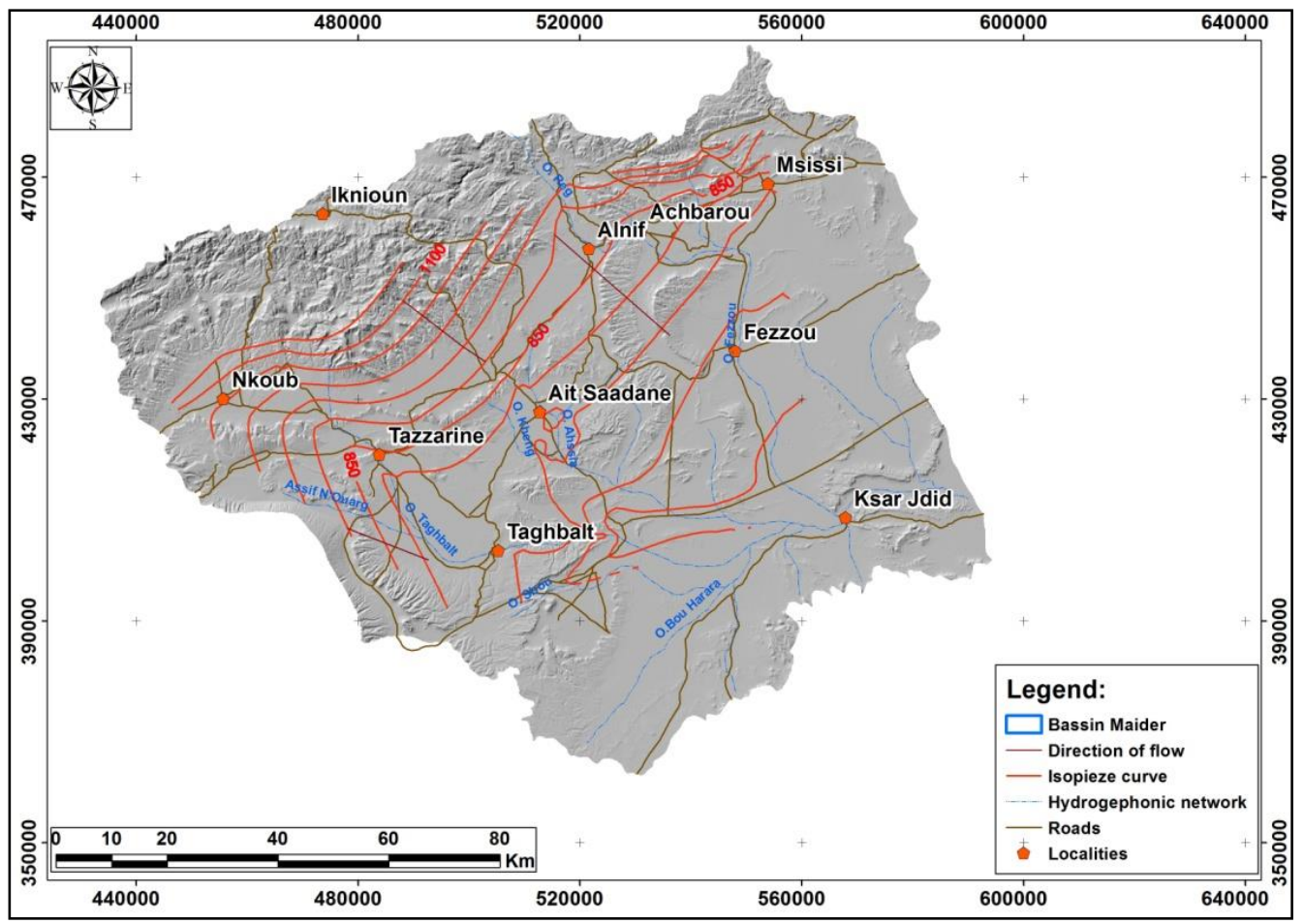

Fig. 3 : The piezometric map of primary aquifer in the Maider basin for year 2017

\subsection{Productivity:}

In totality, the Paleozoic aquifer of the Maider Basin, due to its low porosity (...), does not offer good transmissivities which constitute a hydrodynamic parameter in determining the evaluation of productivity.

From a database of 117 water points (wells and boreholes), well distributed over the study area, the values map of the transmissivity (Figure 3) of the Maider region was realized. It shows, of course, the lowest transmissivities at the west of the basin, while the maximum values are confined at the east, mainly at the level of Alnif upstream.

Concerning flow rates, we tried to recover as much as possible a good coverage of data, so as to have an idea about the state of circulation of groundwater in the basin. FIG. 4 below, which shows the flow distribution, according to values recorded in 132 water points around the basin, obviously shows that the flow rates are largely very low and do not exceed $21 / \mathrm{s}$ for $80 \%$ of the points, while those with relatively high flow rates do not exceed twenty. 


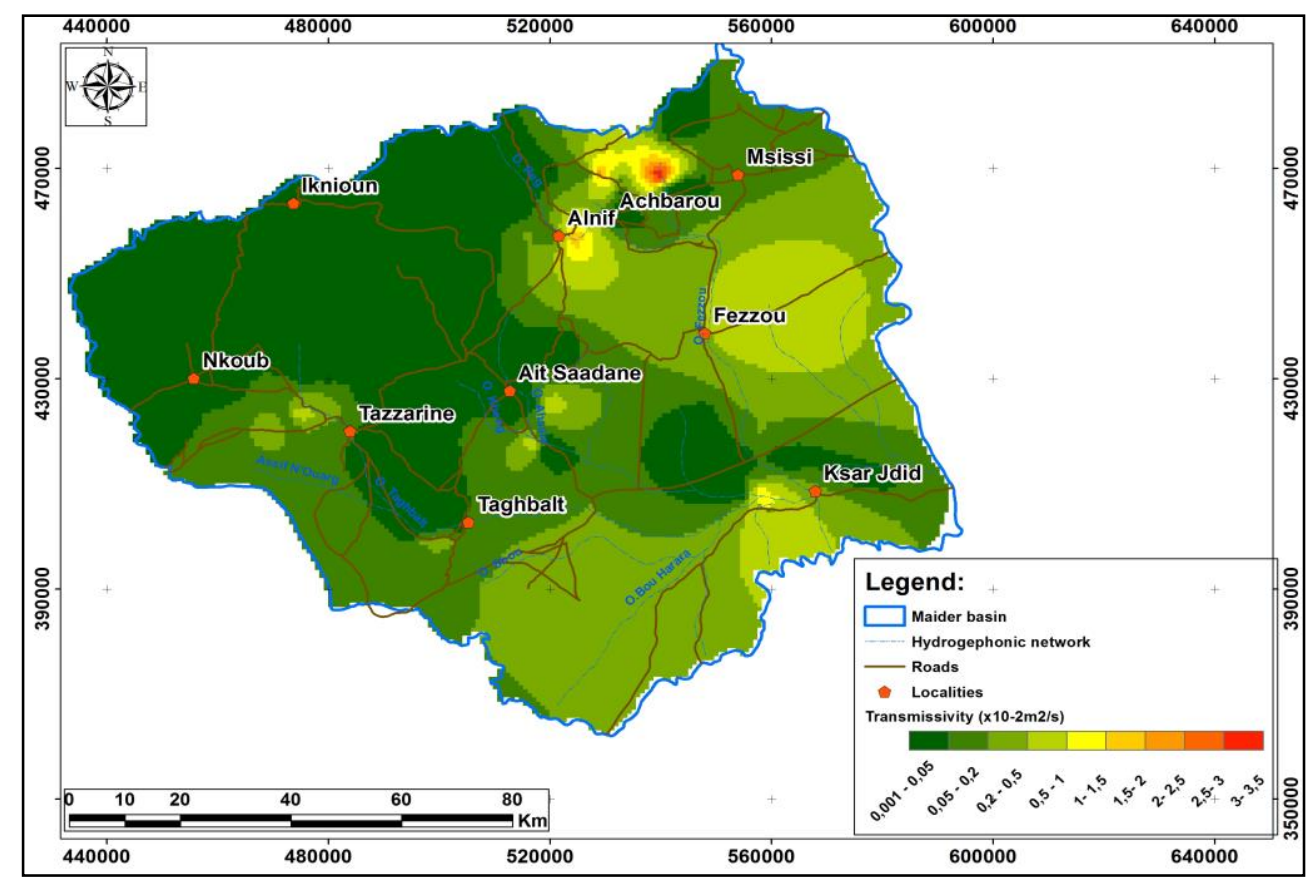

Fig. 4 : the transmissivity Map of primary aquifer in the Maider basin

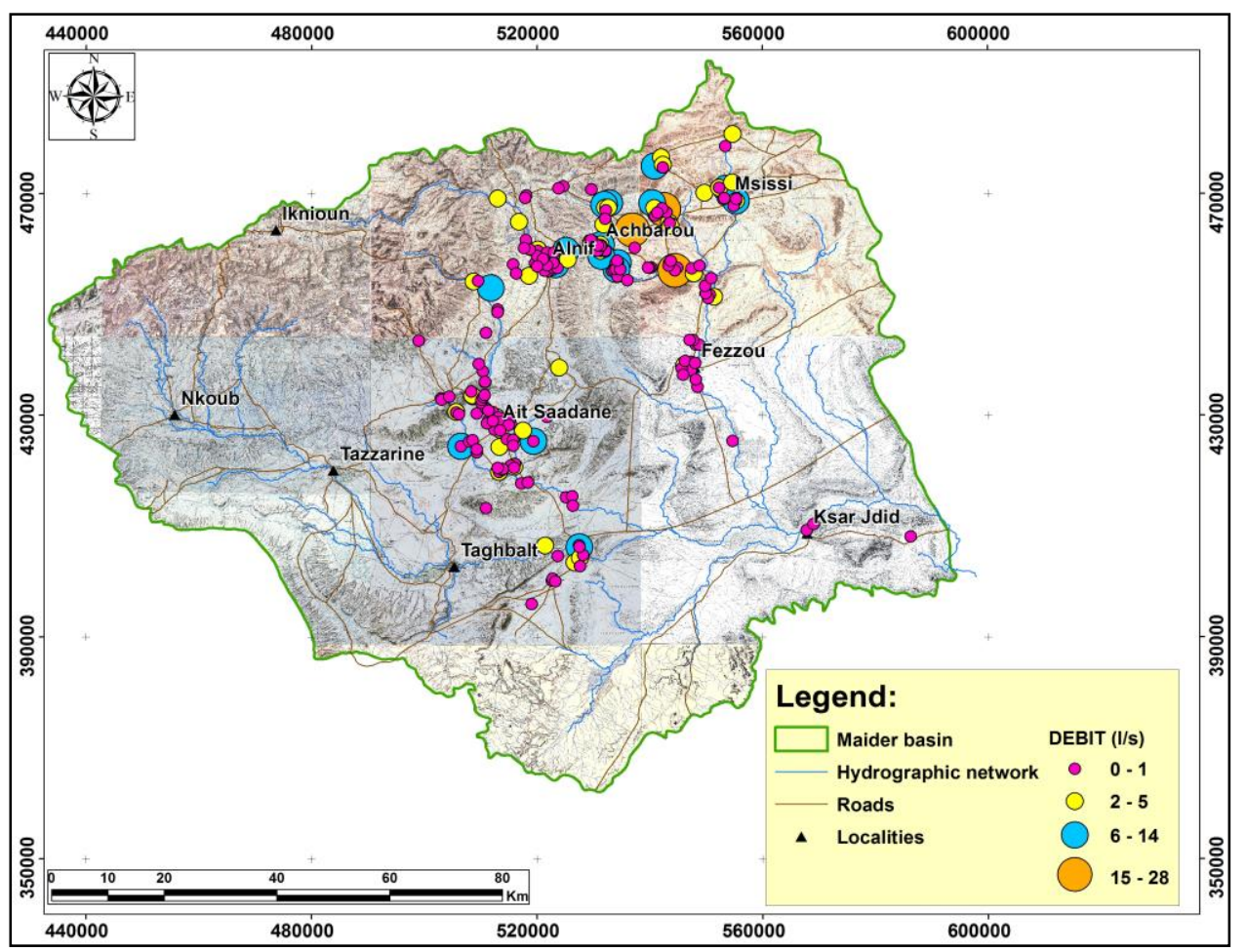

Fig 5 : the distribution map of flow rates in the Maider basin. 


\subsection{Physicochemical Quality :}

To have an idea of the overall quality of groundwater in the basin Maider, we were limited to electrical conductivity. This last is the inverse of the electrical resistivity; it increases with the content of dissolved salts (mineralization). Groundwaters in the basin studied have high values of conductivity in general; which exceed greatly the guide value set by the European standards $(100 \mu \mathrm{S} . \mathrm{cm}-1)$. They are, generally, included between $349 \mu \mathrm{S} . \mathrm{cm}-1$ in the vicinity of Taghbalt, and $5200 \mu \mathrm{S} . \mathrm{cm}-1$ at the south-east of the basin. The map of electrical conductivity (Figure 6) highlights on three groups of different qualities:

- In the eastern portion of the basin (Corridor N'kob-Alnif and basin TazarineTaghbalt), the mineralization of groundwater is relatively good and the electrical conductivity measured does not exceed $1000 \mu \mathrm{S} . \mathrm{cm}-1$.

- In areas that constitute the center and the major part of the basin (the basin of Ait Saadane and the western part of the Fezzou basin), the mineralization of the groundwater is mediocre and the electrical conductivity is between $1000 \mu \mathrm{S}$. cm-1 to more than $3500 \mu \mathrm{S} . \mathrm{cm}-1$.

- In the southern corridor of the basin Tismoumine-Majrane, the mineralization of groundwater which reaches $5400 \mu \mathrm{S}$.cm-1 is much worse, with a tendency towards increase.

The strong mineralization of the water in the basin is generally explained by the lithological nature of the saline formation and by the changes of the hydrological regime, due to the decrease of the water assimilation process caused by drought (significant reduction at the level of the water table).

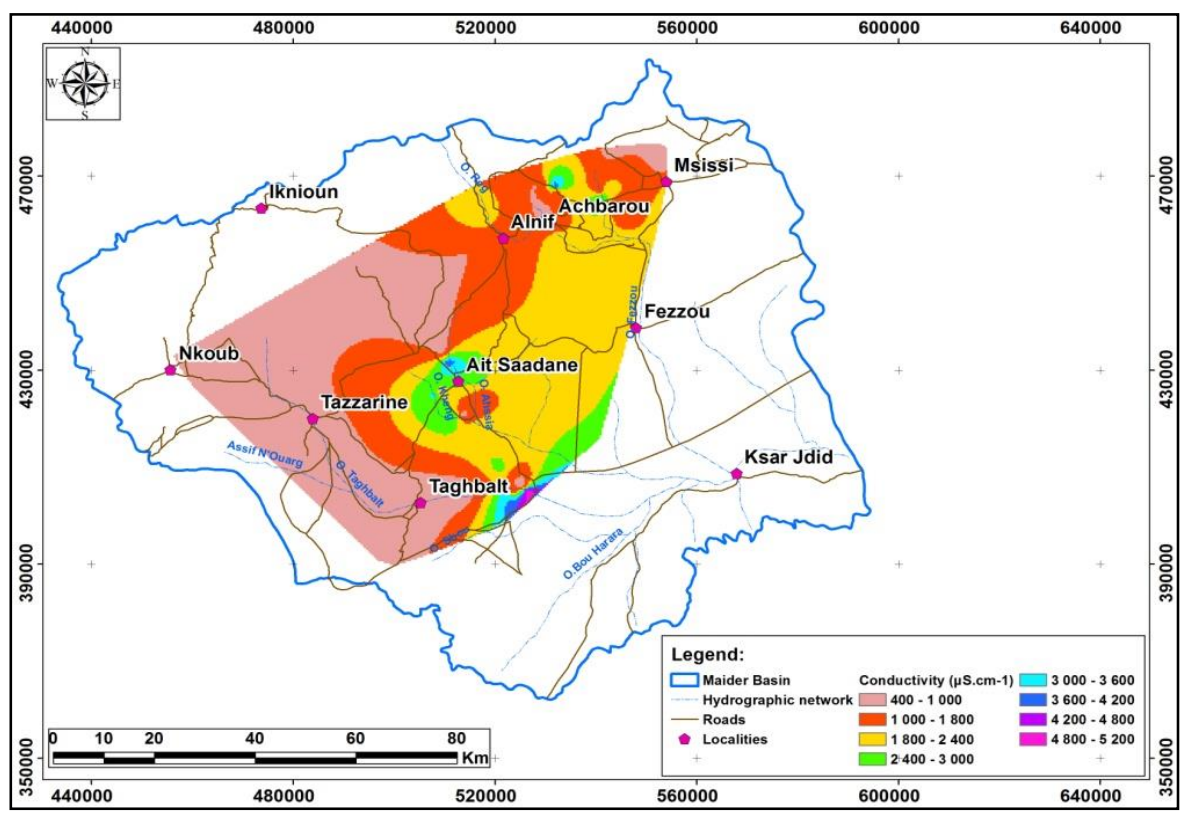

Fig. 6 : the hydraulic conductivity map of the Ordovician Aquifer. 
The temperature degrees of the waters of the ordovician groundwater of Maider basin are between 20.8 and $29.70^{\circ} \mathrm{C}$, with an average of $24.7^{\circ} \mathrm{C}$. They present a lower difference at the Aquifer level; this is due to the fact that the measures have been distributed in a broad interval of time and that the sampling has been carried out at varying depths.

In what concerning the $\mathrm{pH}$ of the groundwater in this basin, it varies between 5.8 and 8.3 , with an average of 7.2 .

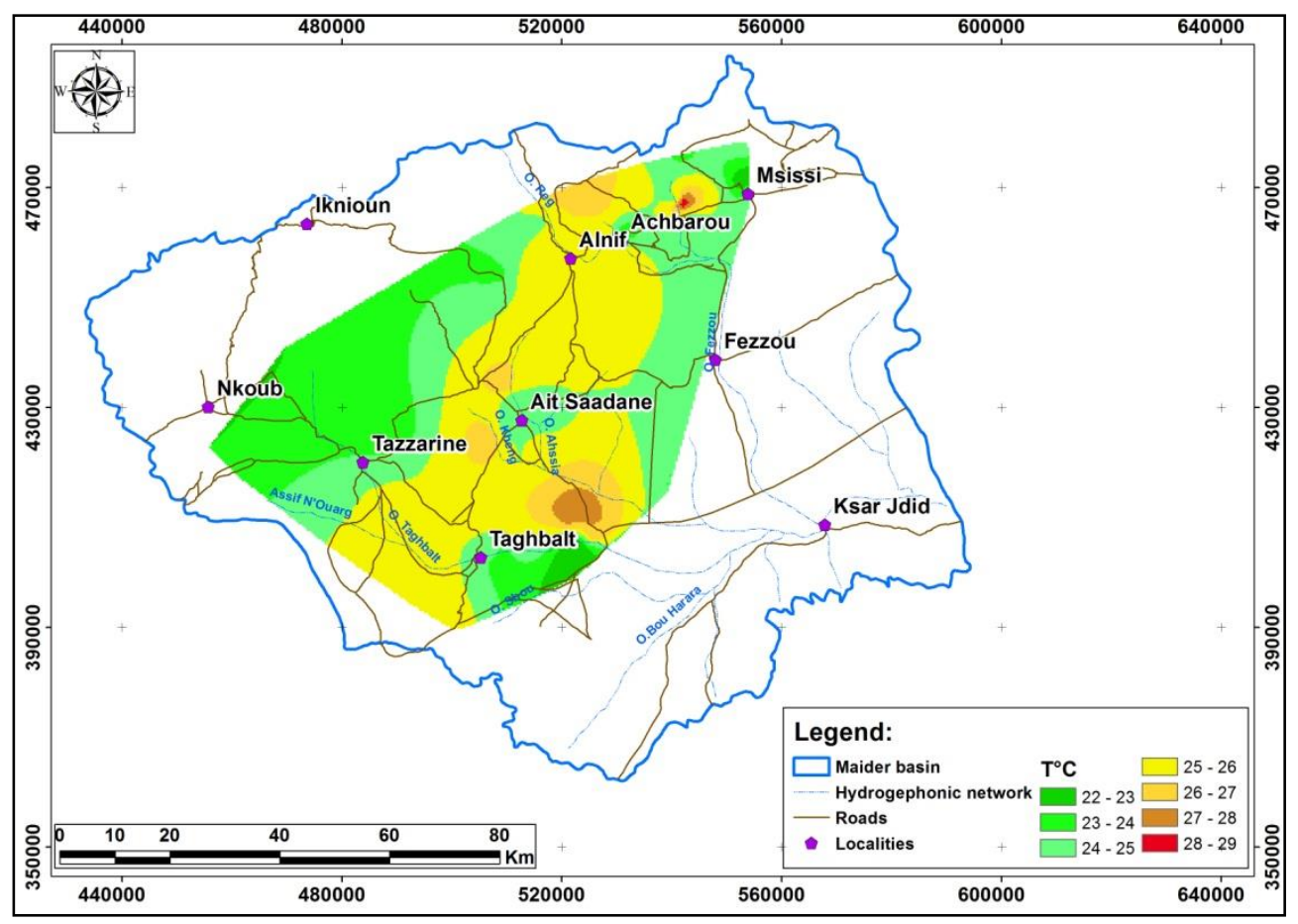

Fig. 7: the temperature Map of the ordovician Aquifer.

\section{Conclusion:}

In this work, we can describe the primary aquifer of the Maider basin and propose some prospects that can be seen pertinent.

- The general flow of the ordovician aquifer is always directed from the north to the south-east of the basin by following the principal axes of the wadis: Taghbalt ,Hssiya and Fezzou.

- View that the studied basin do annually receives about $90 \mathrm{~m}$ of precipitations, it is clearly shown that the recharge aquifer is primarily done, either by the underground flow, or by the surface runoff of torrential waters from the upstream of JBEL SAGHRO. 
- The piezometric anomaly noticed at the level of Ait Saadane (in the center of the basin) that has materialized by the curve $750 \mathrm{~m}$, is explained by an overexploitation of the water table from the fact that this area knows in last years an important extension at the level of irrigated surfaces.

The physicochemical approach for the Maider basin identifies two essential factors for groundwater salinisation: The dissolution of the aquifer formation which is rich in minerals, with high temperature on the one hand, and the decrease of the piezometric surface due to the overexploitation and drought on the other hand.

Although the scarcity and the salinisation of groundwater appear as irreversible phenomena, it is possible to limit their deterioration and their geographical extension. The control of intensive pumping at the whole basin, the use of saving water techniques in irrigation, the artificial recharge of the aquifer, and the demineralization techniques, all these are the main actions to be taken to reduce the risks of the water resources degradation in both: qualitatively and quantitatively sides.

\section{Acknowledgments:}

Our great thanks to the administration and agency staff of the Guir-Ziz-Rhéris Hydraulic Basin of Errachidia to put at our disposal the data used in this article, as well for their assistance and their constructive suggestions. We also thank all those who have contributed in the fullfilment of this work.

\section{References :}

[1] Combe M., Ruhard J.P., \& Yacoub M., (1977) - Présentation du bassin du Maider. In : Ressources eau du Maroc : Domaine atlasique et sud-atlasique, Notes et mémoires du service géologiqque du Maroc, N²31 pp. 416-429.

[2] A. Mouttaqi, E.C. Rjimati, L. Maacha, A. Michard, A. Soulaimani \& H. Ibouh, 2011. LES PRINCIPALES MINES DU MAROC. In: Nouveaux Guides géologiques et miniers du Maroc, vol. 9 (Michard, A., Saddiqi, O., Chalouan, A., Rjimati, E.C., Mouttaqi, A., Eds.). Notes \& Mém. Serv. géol. Maroc, 564, 25-71.

[3] Michard, A.,Hoepffner, A., Soulaimani, A. \& Baidder, L. 2008. The Variscan belt. In Continental Evolution: The Geology of Morocco. Structure, Stratigraphy, and Tectonics of the Africa-Atlantic-Mediterranean Triple Junction (eds A. Michard, A. Chalouan \& O. Saddiqi), pp. 65-132. Lecture Notes in Earth Sciences, 116. Springer-Verlag.

[4] Agence du Bassin Hydraulique du Guir-Ziz-Rhéris (ABH GZR) 2011. Actualisation du Plan Directeur d'Aménagement Intégré des Ressources en Eau des bassins de Guir, Rhéris, Ziz et Maïder (provinces d'Errachidia, Ouarzazate, Zagora et Figuig). Rapport définitif de la mission 1, 91-120. 